\title{
Radiological trends in trampoline-related paediatric injuries in a major paediatric trauma centre: a 6-year experience
}

\author{
Greg Chambers ${ }^{1,2}$ (D) Colin Holton $^{3} \cdot$ Jeannette K. Kraft ${ }^{1}$
}

Received: 2 August 2019 / Accepted: 6 November 2019 / Published online: 3 December 2019

(C) The Author(s) 2019

\begin{abstract}
Aim Review of visits to the radiology department related to trampoline injuries in a major trauma centre in the UK over a 6-year period, and analysis of imaging performed, injury type, and seasonal trends in children under 18 years of age.

Subject and methods Retrospective review of the Radiology Information System (RIS) for requests and reports between January 2012 and December 2017 containing the search term "tramp*" with an age of $<18$ years.

Results A total of 1794 children (44\% male, mean age 8.15) visited the radiology department 1871 times and received 2343 separate radiographic examinations, ten ultrasound examinations, $20 \mathrm{CT}$ examinations, $19 \mathrm{MR}$ examinations and two nuclear medicine examinations. Seven hundred and eighty-eight children (45.9\% male) had injury demonstrated on radiographs (622 fractures and 183 soft-tissue injuries) during 796 visits to radiology. Positive CT, MRI, and US were seen in 55\%, 47.3\%, and $50 \%$ of cases respectively. Children under 7 years of age are more likely to have been injured compared to older children attending for X-rays, with the proportion of injuries seen in 6-year-old children being the highest (63.7\%). Trampoline injuryrelated X-ray requests to radiology rose from $1.7 \%$ to $4 \%$ per year as a percentage of overall X-ray requests from the emergency department.

Conclusion Trampoline injury-related visits to the radiology department and the number of injuries demonstrated on imaging studies have increased over the study period, putting greater pressure on the healthcare system. Younger children are especially prone to injury. Public health campaigns and mandatory national safety standards are needed to increase awareness of potential dangers of recreational trampoline use.
\end{abstract}

Keywords Paediatrics $\cdot$ Musculoskeletal $\cdot$ Emergency $\cdot$ Radiography $\cdot$ Cross-sectional imaging

\section{Introduction}

Recreational trampoline-based activities have increased in recent years. Articles mostly from the United States and Australia report higher volumes of injury, increased severity, and increased hospitalisation rates (Kasmire et al. 2016; Sharwood et al. 2018; Rao et al. 2019; Paul et al. 2016; Purcell and Philpott 2007; Ashby et al. 2015). The National

Greg Chambers

g.chambers@nhs.net

1 Paediatric Radiology Department, Leeds Teaching Hospitals NHS Trust, Leeds, UK

2 Paediatric Radiology Department, Leeds Children's Hospital at Leeds General Infirmary, Leeds LS2 9NS, UK

3 Department of Trauma and Orthopaedics, Leeds Teaching Hospitals NHS Trust, Leeds, UK
Electronic Injury Surveillance system database recorded 288,876 trampoline fractures with an estimated 1,002,735 visits to emergency departments in the US from 2002 to 2011 (Loder et al. 2014). The American Academy of Pediatrics, Safe Kids Canada, the Canadian Paediatric Society and Canadian Academy of Sport and Exercise Medicine released policy statements and safety recommendations with regard to recreational trampoline use (Purcell and Philpott 2007; Briskin and LaBotz 2012). At the turn of the century, the sales of domestic garden trampolines rose, but in recent years the focus has shifted to newly setup trampoline parks. Reports in the scientific literature and mainstream press have warned about injuries sustained in trampoline parks, raising questions about safety regulations (Kasmire et al. 2016; Sharwood et al. 2018; Rao et al. 2019; Paul et al. 2016; Wootton and Harris 2009; BBC News 2018; Mulligan et al. 2017; The Guardian 2017). Only a small number of older studies, examining limited numbers of patients with 
trampoline-related injuries, are available from the UK and Europe (Wootton and Harris 2009; Bhangal et al. 2006; Eberl et al. 2009; McDermott et al. 2006; Klimek et al. 2013). Our study aims to assess the workload in the radiology department related to these injuries, in a large tertiary referral major trauma centre in the UK, to identify trends in number of attendances, injury type, and severity.

\section{Methods}

A retrospective search of the local radiology information system (RIS) for emergency department (ED) requests and reports between January 2012 and December 2017, containing the search term "tramp*" with an age of $<18$ years was used. Modalities included were radiography, computed tomography (CT), magnetic resonance imaging (MRI), ultrasound (US) and nuclear medicine (NM).

Radiological reports were reviewed and categorised as positive or negative for injury. Fractures and soft-tissue injury (including soft-tissue swelling and joint effusions) were regarded "positive". Radiological reports identifying a fracture with associated soft-tissue injury were counted as a single injury ('fracture'), as were recognised patterns of injury,e.g., concomitant fractures of the distal radius and ulna.

All other reports were classed "negative" for injury. The date of injury was recorded for each attendance to the radiology department as well as patient demographic data; age, sex, body part injured, and number of body parts imaged. For any reports where clinical correlation was advised for equivocal findings, the follow-up imaging and records were reviewed. Any patients treated clinically as fractures, with or without imaging evidence for injury, were counted as positive.

Cross-sectional imaging and NM reports were categorised as positive or negative, and the injury type recorded along with the demographics.

\section{Results}

\section{Modality}

The RIS search of yielded 1832 visits to the radiology department for X-ray examinations in 72 months. Eight duplicate attendances (four post-manipulation studies, four follow-up studies) and four attendances for non-trampoline-related injuries were excluded, leaving $1820 \mathrm{X}$-ray visits (2343 separate radiographic examinations) for analysis from the ED.

Fifteen ultrasound visits were identified (of which five were excluded for non-trampoline-related injuries), imaging 17 body parts and two nuclear medicine studies (bone scans for scaphoid injury), which were both negative and will not be further discussed.
Twenty-one CT visits were identified with 20 eligible for analysis (one excluded patient was "trampled" by a horse) covering 28 body parts. There were 21 MRI visits, with 19 eligible for analysis after excluding non-trampoline-related injuries, with 28 body parts imaged

In total, 1794 children visited radiology 1871 times with 2343 total radiological examinations for analysis between 2012 and 2017.

\section{Radiographs - patterns of injury}

Overall, 1743 children (mean age 8.1 years) visited 1820 times with trampoline-related injuries during the review period (mean $=25.3$ attendances per month) and received 2343 separate radiographic examinations (mean $=1.3$ radiographs per attendance). Thirty-eight of the children with a positive visit also attended with a separate negative visit at a different time. Positive examinations were seen in 788 children visiting radiology 796 times (eight children visited twice for separate episodes). Nine children had two concurrent injuries, e.g., bilateral elbow dislocations. Therefore, 805 injuries were seen in 788 children over 796 visits, requiring 928 radiographic examinations (Fig. 1).

Of these 928 examinations, 60/928 radiographs $(6.5 \%)$ identified the same injury as a concurrent exam, e.g., a distal fibula fracture also seen on an ankle radiograph. A further $63 / 928$ radiographs $(6.8 \%)$ demonstrated no injury, but were performed concurrently with a positive study, e.g., radial head fracture on an elbow radiograph with a normal wrist view. These radiographs were not further analysed or considered positive. Of the positive visits (796), 614 children $(77.1 \%)$ had at least one fracture and $182(22.9 \%)$ had soft-tissue injury only. Eight patients' imaging demonstrated two separate fractured body parts, and one patient had a separate soft-tissue injury remote to their fracture site. The total number of injuries was therefore 622 fractures, and 183 soft-tissue injuries (a total of 805 injuries) in 614 children. No injury was identified in 993 children during 1024 visits requiring 1415 separate radiographic examinations. Twenty children attended twice, three children thrice and one child six separate times during the study period, totalling 31 repeat visits. None of the repeat visits were to reinvestigate previous negative findings.

The most commonly examined body parts were ankles (17.8\%), feet (12.1\%), and elbows (9.0\%). Elbows (18.5\%), wrists $(18.0 \%)$, ankles $(15.4 \%)$, and knees $(14.0 \%)$ were the most commonly fractured body parts, with ankles $(65.6 \%)$, elbows $(15.8 \%)$, and knees $(6.6 \%)$ being the most common sites of soft-tissue injury (Fig. 2).

Patients with radiographic examinations identifying an injury were on average 1.3 years younger than children without demonstrable injury; 7.5 years versus 8.8 years. Children under 7 years are more likely to have an injury than older 


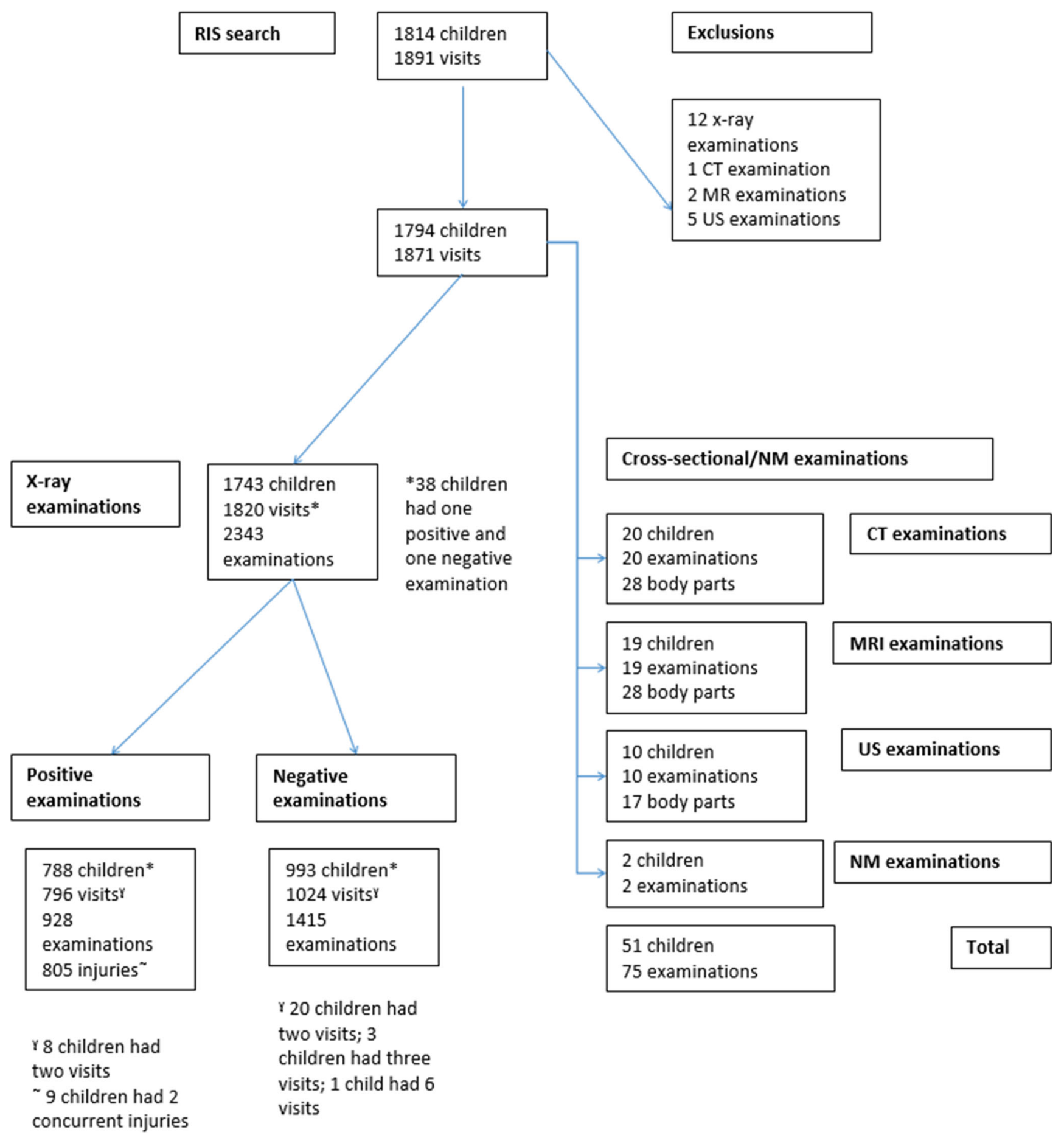

Fig. 1 Flow chart showing the number of children, visits and examinations by modality

children attending for X-rays. In children 7 years and under, there were 434 injuries on $784 \mathrm{X}$-ray visits (55.3\%), compared to 8 years and over with 362 injuries on 1036 visits (34.9\%). The proportion of injuries was the highest at 6 years old (63.7\%). Older teenagers between 14 and 17 years are least likely to attend with trampoline-related injuries, making up just 170 out of the 1820 overall visits to radiology (9.3\%) (Fig. 3).

\section{Trends}

Between 2012 and 2017 attendances to radiology with trampoline-related injuries rose by $118 \%$ (218 to 476 ). The largest year-on-year rise was a $42 \%$ increase from 2014 to 2015. Despite rising numbers of attendances, the proportion of positive findings remained stable (between $40.8 \%$ and $50.4 \%$ per year) (Fig. 4). In our study period, 74,447 
Fig. 2 "Heat map" of 622 confirmed fractures by body part and percentage of total injuries. Elbows, wrists, ankles and knees suffer the highest proportion of fractures. There were no recorded head, neck or abdominal-region fractures on radiographs, which likely reflects the lack of use of $\mathrm{x}$ rays in the setting of head, neck and abdominal trauma

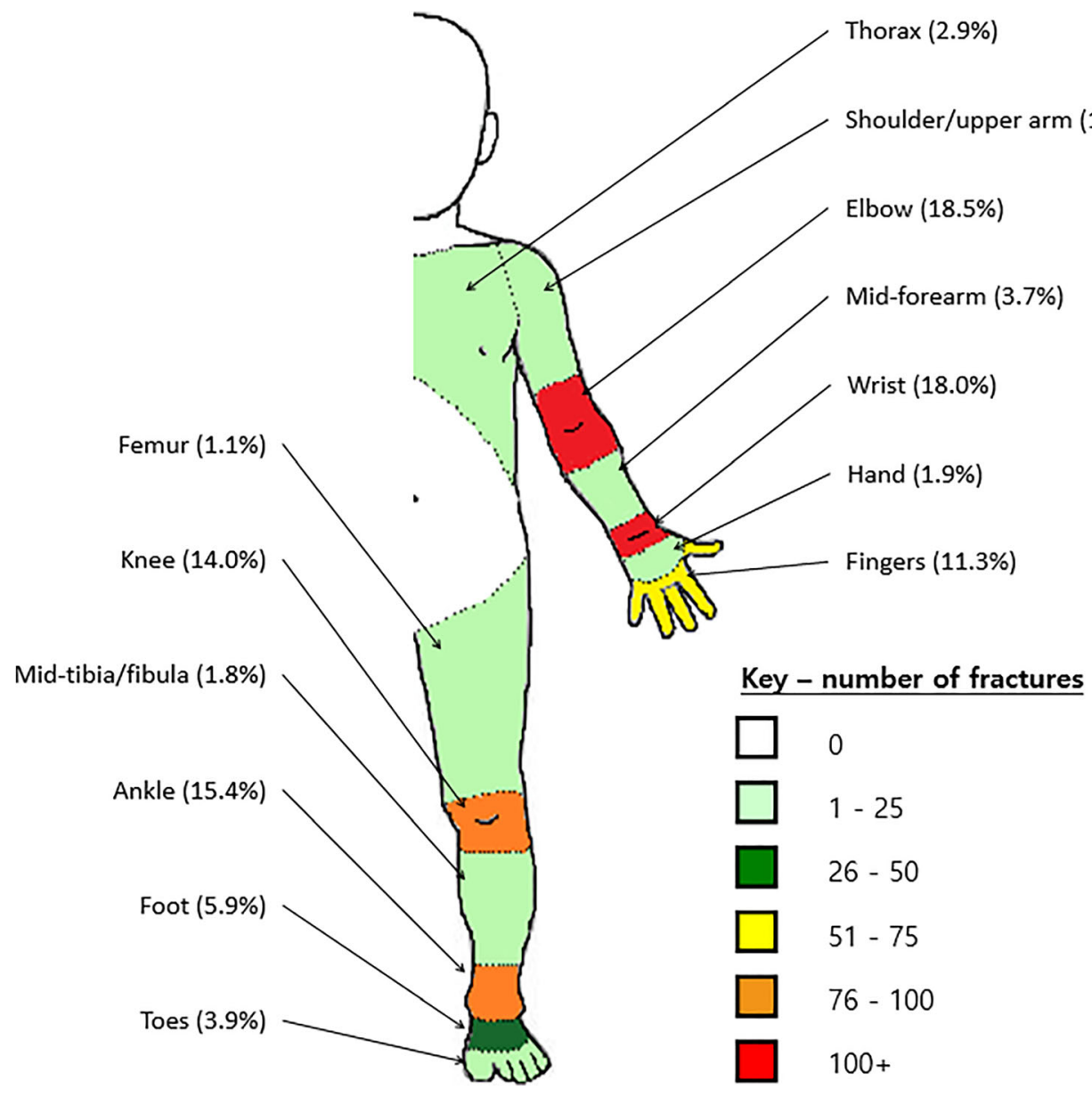

trauma-related radiographic studies were undertaken in children attending the emergency department. Therefore, this represents approximately $2.4 \%$ of our workflow in total. However, year-on-year there has been a gradual rise from $1.7 \%$ in 2012 to $4 \%$ in 2017.

More children presented during the spring and summer months (April to August), with fewer attendances in the winter months (October to February). Comparing the number of children attending from 2012 to 2014 with 2015 to 2017, patient numbers increased all year round (Fig. 5). However, analysing the number of children attending as a proportion of all visits for trampoline-related injuries, the number of attendances in the winter months increased from $13 \%$ to $23 \%$ in the second half of our study period (Fig. 6).

\section{MRI/CT — patterns of injury}

Twenty children ( $35 \%$ male, mean age 10.9 years, range $2-$ 17 years) had CT scans imaging 28 body parts. No child had more than one CT scan. Seventeen CT scans (85\%) were carried out acutely within $24 \mathrm{~h}$ of injury, the remaining three in the sub-acute setting. Eleven patients $(55 \%)$ had positive findings, with eight of these performed acutely; five head injuries, one spinal fracture, and two limb fractures. A midfoot fracture and two limb fractures were diagnosed in the sub-acute setting, after orthopaedic evaluation and initially radiographically-occult injuries. All negative scans were performed acutely.

Nineteen children $(15.8 \%$ male, mean age 11.4 years, range $3-16$ years) had MR scans imaging 28 body parts. No child had more than one MRI scan. Two MR scans (10.6\%) were undertaken acutely within $24 \mathrm{~h}$ of injury. Nine children $(47.3 \%)$ had positive findings, with seven $(77.8 \%)$ of these performed sub-acutely, including one child with incidental inflammatory joint disease but no injury. A cervical spine fracture-dislocation, a proximal tibial fracture that was equivocal on initial radiography, and soft-tissue injuries were diagnosed. All negative scans were performed sub-acutely. One 3year-old patient required general anaesthesia. Cross-sectional imaging was required in $2.1 \%$ of patients (39/1871 visits) overall.

\section{Trends}

Use of cross-sectional imaging has shown a general rise over the study period, but overall numbers remained small. 


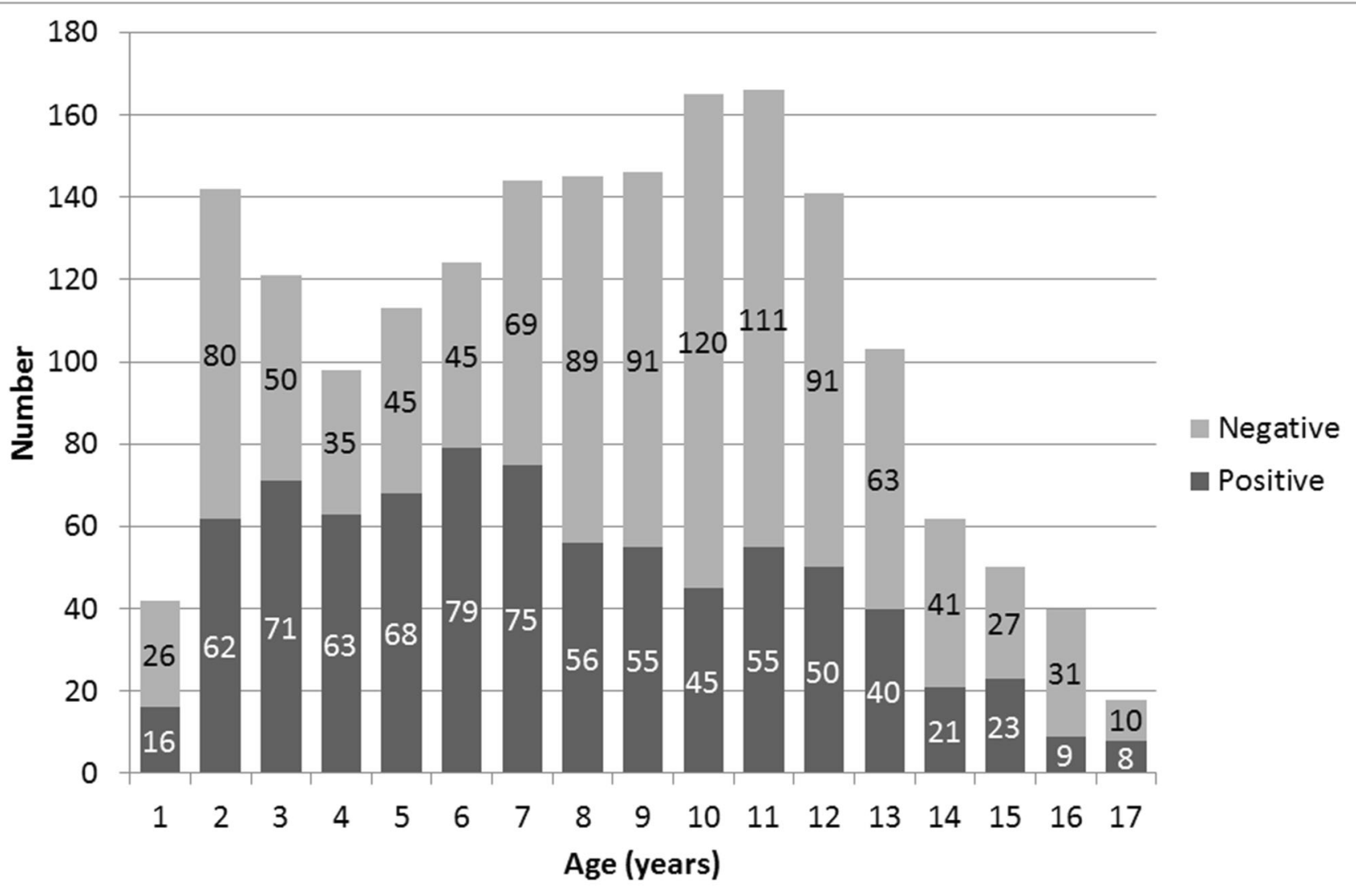

Fig. 3 The age distribution of patients attending radiology for X-ray examinations between 2012 and 2017. The greatest proportion of injury is seen in 6-year-old children. There are peaks in visits at 2 years and 10-
11 years old. Number of patients and injuries drop off steeply from 14 years old onwards
Numbers of performed CT scans rose from two in 2012 to six in 2017. Sixty-five percent of all scans (13/20) were performed during 2016-2017.

The use of MR imaging has increased, with two scans performed in 2012 rising to five in 2017. Fifty-eight percent of MR scans (11/19) were performed during the last 2 years of the study period 2016-2017.

\section{Ultrasound — patterns of injury}

Ten children (50\% male, mean age 8.7 ) had US examinations of 27 body parts. Five patients had scans of both hips and both knees, two patients had abdominal ultrasound scans, two patients had lower leg scans, one child a testes scan, one child a chest wall scan, and one patient an Achilles' tendon examination. There were five positive studies (50\%), of which three were incidental and unrelated to trampoline injury (transient synovitis of the hip in two patients, a testicular varicocoele in one patient). Two trampoline-related positive scans showed a knee effusion with soft-tissue haematoma, and fat necrosis in the soft tissues of the calf. All scans were performed in the sub-acute setting.

\section{Trends}

Numbers of ultrasound scans are low, and there has been no significant change during the study period. At least one scan was performed in each year,with the highest number of scans (three out of ten) performed in 2015.

\section{Discussion}

Multiple publications warn of the dangers related to recreational trampoline use (Sharwood et al. 2018; Purcell and Philpott 2007; Briskin and LaBotz 2012; Rättyä and Serlo 2008; AAOS 2015). The American Academy of Pediatrics, Safe Kids Canada, the Canadian Paediatric Society, and Canadian Academy of Sport and Exercise Medicine have issued statements against the use of trampolines in the home environment (Purcell and Philpott 2007; Briskin and LaBotz 2012; CPS 2017). Efforts to make trampoline use safer through improved design, such as the inclusion of safety nets, and recommending adult supervision have not had the desired impact (Wilson et al. 2018; Paker 2017). Trampoline safety 


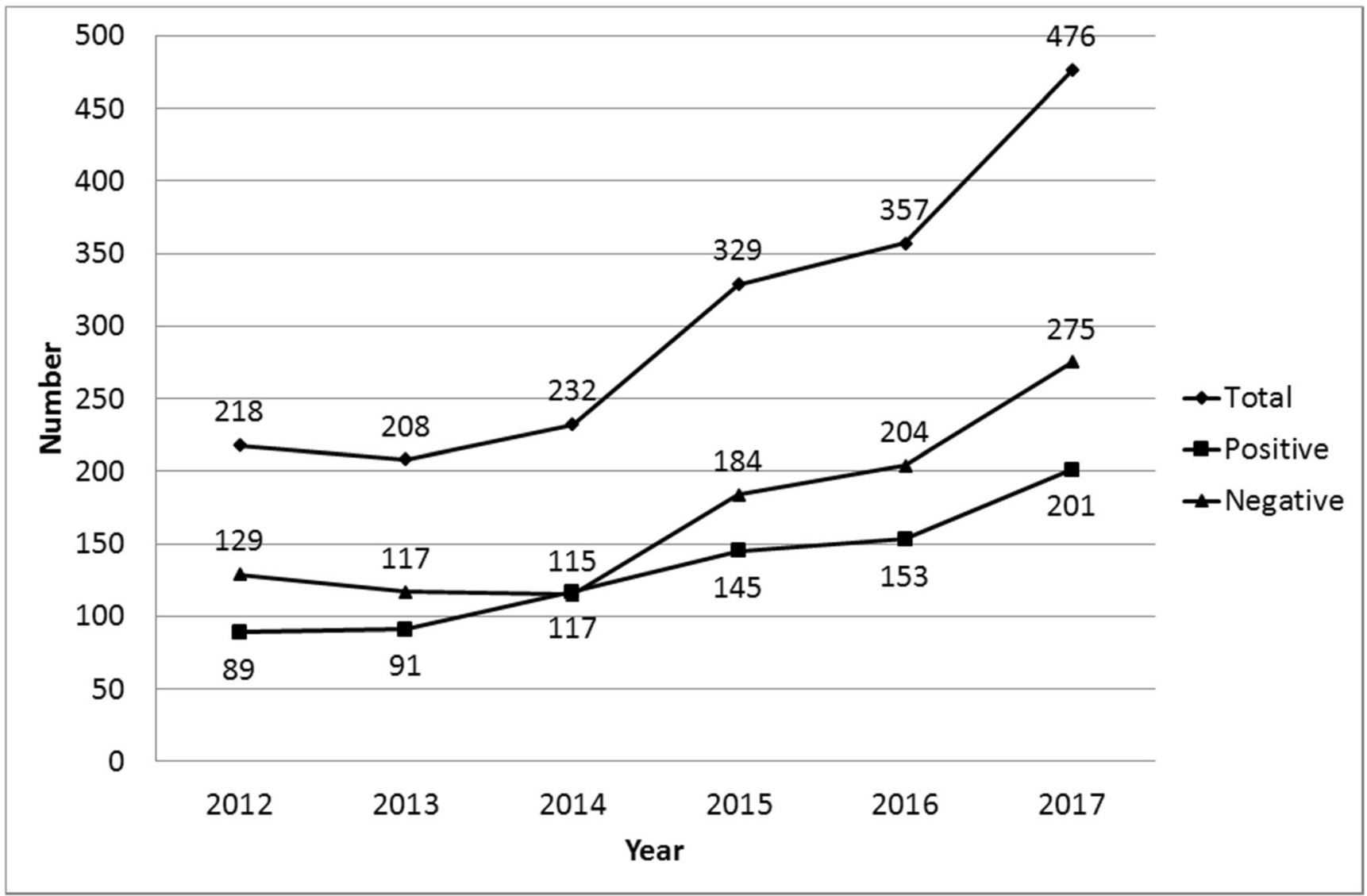

Fig. 4 Radiology attendances from 2012 to 2017. A relatively stable number of visits to Radiology was seen from 2012 to 2014, with large consecutive rises in 2015,2016 , and 2017. Proportionally, the number of studies positive and negative for injury per year has remained stable

knowledge among parents remains low, despite parents being in the best position to promote safer recreational use of trampolines (Beno et al. 2018). Our study confirms that trampolining's popularity in a large city in the UK is on the increase, mirroring findings from the US, Canada, and Australia (Kasmire et al. 2016; Sharwood et al. 2018; Rao et al. 2019; Ashby et al. 2015). Our results show a significant year-onyear increase in trampoline-related injuries starting around
Fig. 5 Number of children attending radiology with trampoline-related injuries per month in the years 2012-2014 and 2015-2017. From 2012 to 2014 , a peak is seen in the spring and summer months, with fewer children attending in the winter months. In the second half of our study period from 2015 to 2017 more children presented in the winter months, which may be linked to increased availability of indoor facilities

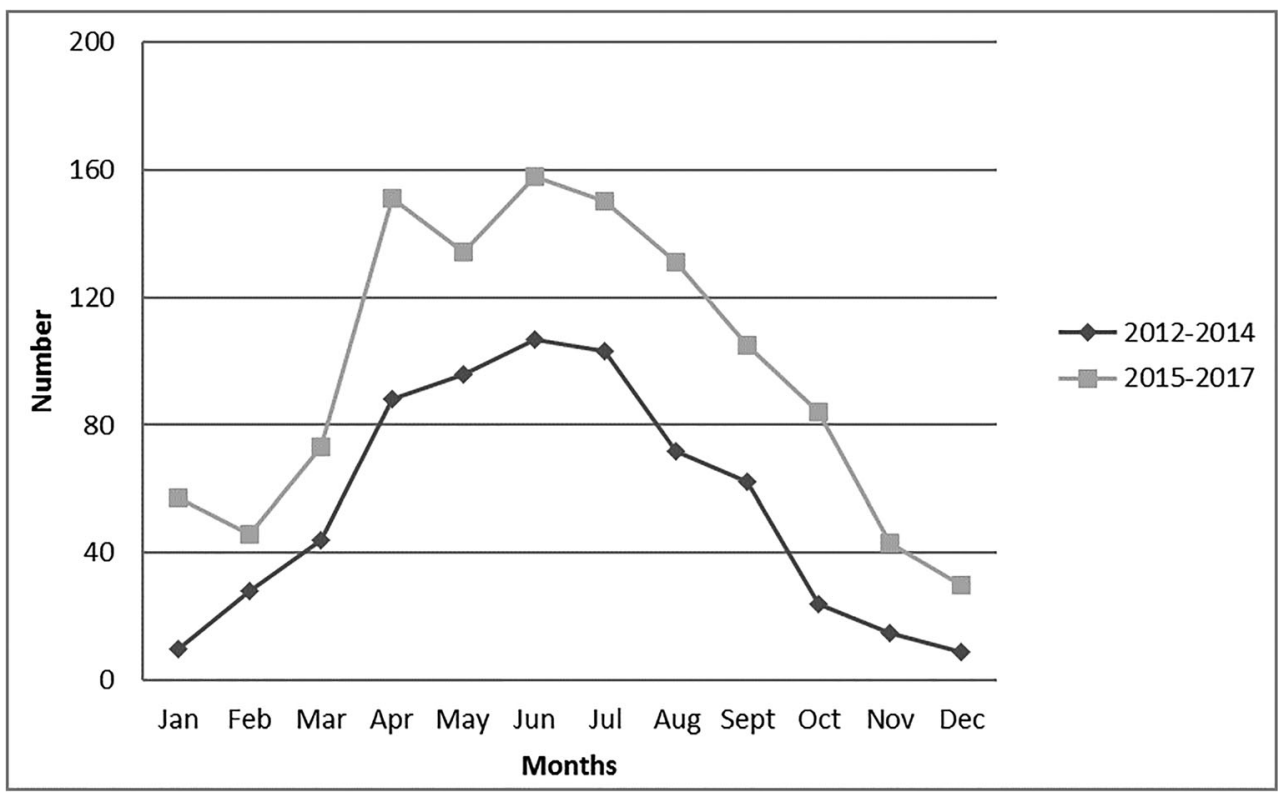




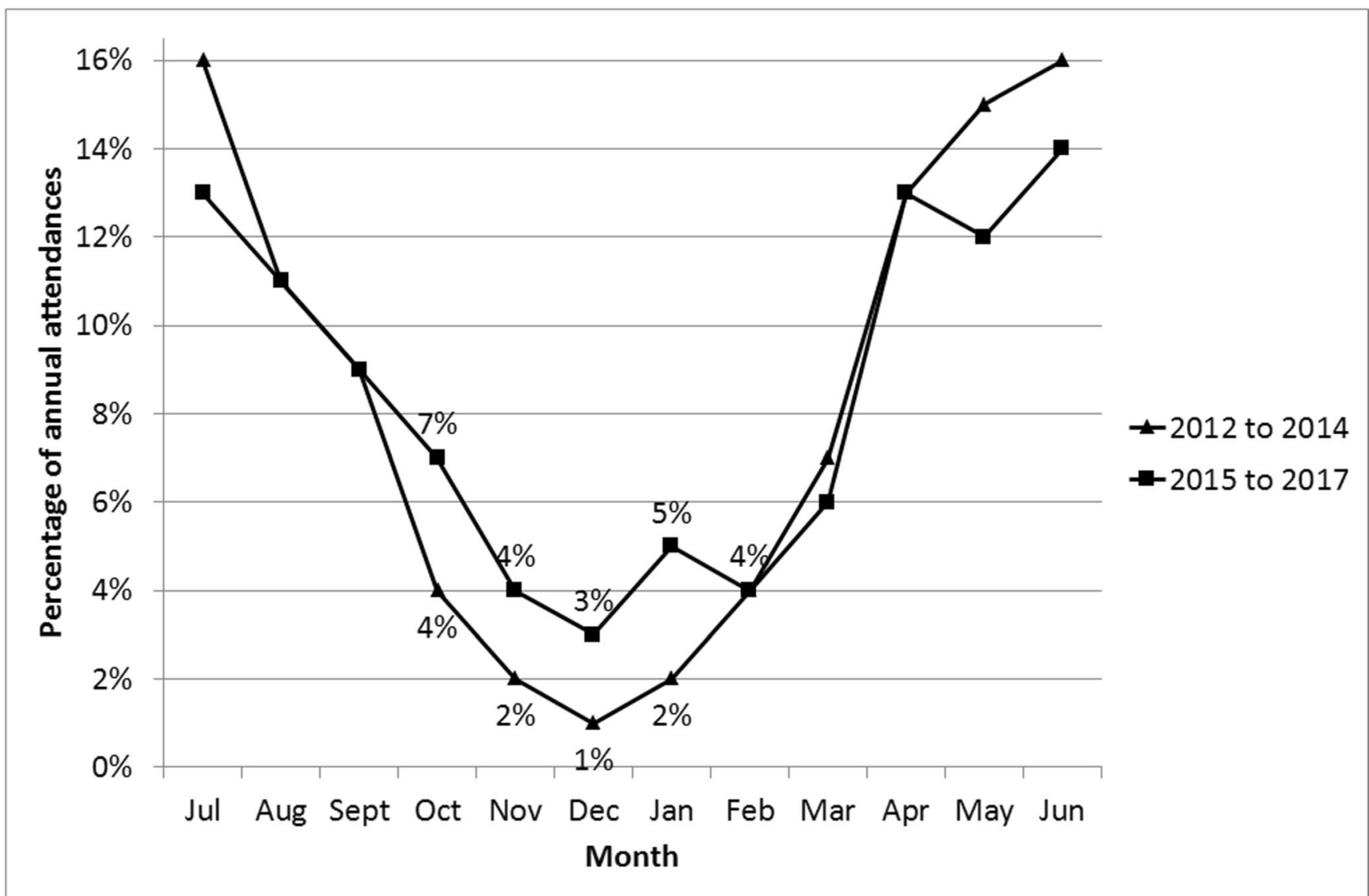

Fig. 6 Number of children presenting each month to radiology as a percentage of overall annual attendances with trampoline-related injuries per year (pooled over 3-year periods: 2012-2014 and 2015-2017). The

the same time that the first trampoline park opened nearby in 2015. In 2017, there were at least 3 trampoline parks in our region.

In our study, the upper extremity was more commonly injured with most injuries at the elbow (18.5\%), followed by the wrist (18\%), ankle (15.4\%), and knee (14\%). This corresponds to findings from previous studies (Loder et al. 2014; Klimek et al. 2013). There is new evidence to suggest that the patterns of injuries are different depending on the location of the trampoline, with upper limb and head injuries being more common in a backyard setting, and lower limb injuries in the indoor setting (Kasmire et al. 2016). This might be related to inadequate padding and netting used in the backyard setting; and new indoor trampoline sites are often 'wall-to-wall' reducing the risk of a hard landing. It was not possible to observe this trend in our study due to the lack of data relating to the location of the trampoline where the injuries occurred.

In our cohort, the number of injuries over the winter months increased, which may be linked to the fact that indoor trampoline parks allow sporting activity regardless of the season. Interestingly, a Korean study reported no seasonal variation in trampoline-related injuries, which was attributed to the high number of injuries sustained in number of attendances in the winter months increased from $13 \%$ to $23 \%$ in the second half of our study period. Whilst a summer predominance remains, more children are presenting all year round

trampoline parks (67\%) (Choi et al. 2018). However, like most studies from America and Australia, the spring and summer months remain a peak time for injuries in our study (Eberl et al. 2009; Yule et al. 2016). The injuries sustained in winter are not simply 'replacing' the injuries sustained in summer, but adding to them, leading to an overall increase in visits to the radiology department over the study period. This could however also be related to more children taking up exercise in form of trampolining in the winter months rather than being more sedentary, or that other sporting activities are replaced by trampolining.

Our results show that younger patients ( 7 years of age and less) are more likely to have sustained an injury when they present to imaging departments. This was also observed in a limited number of previous studies (Ashby et al. 2015; Choi et al. 2018). Smaller children are up to 13.6 times more likely than larger children to sustain injuries on a trampoline (Hurson et al. 2007). A study by Choi et al. (2018) reports that more than half of the injured children in multi-user events were the youngest on the trampoline at the time. This is most likely related to the lower body weight and less developed motor skills of small children. Multiple organisations have advocated specific paediatric limitations on trampoline use, and called for no 
participation by children younger than 6 years of age (Purcell and Philpott 2007; AAOS 2015; Health Canada 2005).

Thirty-nine of 1871 patients $(2.1 \%)$ had severe enough clinical injury to undergo cross-sectional imaging, acutely or in the sub-acute setting with CT or MR. Of these, 21/39 (54\%) had clinically important findings - overall 21/1871 (1.1\%) - which are often occult on plain radiographs. Hauth et al. (2017) reviewed MR scans of 20 children with trampolinerelated injuries, and suggested 'generous use of MR imaging' in children with ongoing pain after trampoline injury and negative initial plain radiographs. Such injuries, especially of the head and spine, can have life-changing consequences (Wechsler et al. 2001; Leonard and Joffe 2009).

Published statements and recommendations on the recreational use of trampolines have advised caution and restrictions on its use (Purcell and Philpott 2007; Briskin and LaBotz 2012; AAOS 2015; Health Canada 2005; CPSC 2012; Government of Western Australia 2015; Murphy 2000). This includes advice that trampolines should not be regarded as play equipment, requiring adequate constant adult supervision, strictly one person jumping at the time, use of shock-absorbing pads and enclosure netting, and no somersaults or tricks. The use by children less than 6 years of age is discouraged. Ideally, trampolines should only be used in a supervised setting with trained personnel in a recognised training environment such as the British Gymnastic Program (British Gymnastics 2009). The Royal Society for the Prevention of Accidents $(2011,2015)$ aided by National Health Service Trusts in the UK have published advice on garden trampoline safety.

Supervision at indoor parks currently has no mandatory regulation and can vary from site to site. To participate, parents or guardians must sign waivers for their children, which provide safety rules for the park, but do not always outline potential injuries that may be sustained (Bounce 2018). Due to increasing numbers of injuries seen in indoor trampoline parks in Australia, Sharwood et al. (2018) have called for national mandatory safety standards that apply to indoor trampoline park operators and might help to reduce injuries. General guidelines and standards for the UK and Europe aiming to increase public awareness and to prevent injury while using trampolines recreationally appear to be limited.

Our study was retrospective, with limited information on trampoline location at the time of injury. We could not establish a definite causative link for the rise in injuries. Another limiting factor was the use of a key term search in reports and requests. The true incidence of injury may have been underestimated if clinicians did not mention the key search term 'tramp*' in their clinical details. Cross-sectional imaging was used as a radiological surrogate for a potentially severe injury, but this did not consider clinically severe orthopaedic injury, for example open or markedly displaced fractures, separately. Therefore, the $1.1 \%$ of severe injuries in our study is probably an underestimate. Finally, this study only deals with imaging at initial acute presentation, and therefore does not consider the protracted clinical and imaging follow-up that may be required in a significant proportion of cases.

\section{Conclusion}

The number of trampoline-related injuries has increased over the study period. Higher injury rates are seen in younger children. Seasonal trends appear to be altering as access to indoor trampolines widens. This leads to more emergency and radiology department visits all year round and places an increased burden on the healthcare system. More campaigns are needed to improve public awareness on how to prevent trampolinerelated injuries by providing guidance to parents and carers and influence national policies to set safety standards.

\section{Compliance with ethical standards}

Conflict of interest None.

Ethical approval None required.

Open Access This article is distributed under the terms of the Creative Commons Attribution 4.0 International License (http:// creativecommons.org/licenses/by/4.0/), which permits unrestricted use, distribution, and reproduction in any medium, provided you give appropriate credit to the original author(s) and the source, provide a link to the Creative Commons license, and indicate if changes were made.

\section{References}

American Academy of Orthpaedic Surgeons (AAOS) (2015) AAOS position statement: trampolines and trampoline safety, Position Statement 1135. https://aaos.org/uploadedFiles/PreProduction/ About/Opinion_Statements/position/1135TrampolinesandTrampolineSafety.pdf. Accessed 28 Jul 2019

Ashby K, Pointer S, Eager D, Day L (2015) Australian trampoline injury patterns and trends. Aust NZ J Public Health 39:491-494. https:// doi.org/10.1111/1753-6405.12404

BBC News (2018) Trampoline parks: Regulation calls after injuries increase. Available online at: https://www.bbc.com/news/uk-england43261578, 2018. Accessed 28 Jul 2019

Beno S, Ackery A, Colaco K, Boutis K (2018) Parental knowledge of trampoline safety in children. Acad Pediatr 18:166-171. https://doi. org/10.1016/j.acap.2017.03.015

Bhangal K, Neen D, Dodds R (2006) Incidence of trampoline related pediatric fractures in a large district general hospital in the United Kingdom: lessons to be learnt. Inj Prev 12:133-134. https://doi.org/ 10.1136/ip.2005.010314

Bounce (2018) Injury waiver and general release form. Available online at: https://www.bouncegb.com/img/safety/Waiver-Under18.pdf. Accessed 28 Jul 2019

Briskin S, LaBotz M (2012) Trampoline safety in childhood and adolescence. Pediatrics 130:774-779. https://doi.org/10.1542/peds.20122082 
British Gymnastics (2009) Garden trampoline safety. Available online at: https://www.british-gymnastics.org/clubs/club-membership/ document-downloads/health-safety/1591-garden-trampoline-safetystatement/file. Accessed 28 Jul 2019

Canadian Pediatric Society (CPS) (2017) Are recreational trampolines safe? https://www.caringforkids.cps.ca/handouts/home trampolines. Accessed 28 Jul 2019

Choi E, Hong J, Sim J (2018) Distinct features of trampoline-related orthopedic injuries in children aged under 6 years. Injury 49:443446. https://doi.org/10.1016/j.injury.2017.12.017

Consumer product safety comission (CPSC) (2012) Trampoline Safety. Available online at: https://www.cpsc.gov/PageFiles/137868/ 085TrampolineSafety.pdf. Accessed 28 Jul 2019

Eberl R, Schalamon J, Singer G, Huber S, Spitzer P, Höllwarth M (2009) Trampoline-related injuries in childhood. Eur J Pediatr 168:11711174. https://doi.org/10.1007/s00431-008-0897-5

Government of Western Australia (2015) Trampolines are not toys. Available online at; https://www.commerce.wa.gov.au/sites/default/ files/atoms/files/safetyforkidstrampolines.pdf. Accessed 28 Jul 2019

Hauth E, Jaeger H, Luckey P, Beer M (2017) MR imaging for detection of trampoline injuries in children. BMC Pediatr 17:27-32. https://doi. org/10.1186/s12887-017-0791-2

Health Canada (2005) Trampoline safety. Available online at: https:// www.canada.ca/content/dam/hc-sc/migration/hc-sc/hl-vs/alt formats/pacrb-dgapcr/pdf/iyh-vsv/prod/trampoline-eng.pdf. Accessed 28 Jul 2019

Hurson C, Browne K, Callender O, O'Donnell T, O'Neill A, Moore D, Fogarty E, Dowling F (2007) Pediatric trampoline injuries. J Pediatr Orthop 27:729-732. https://doi.org/10.1097/BPO. 0b013e318155ab1

Kasmire K, Rogers S, Sturm J (2016) Trampoline park and home trampoline injuries. Pediatrics 138:e20161236. https://doi.org/10.1542/ peds.2016-1236

Klimek P, Juen D, Stranzinger E, Wolf R, Slongo T (2013) Trampoline related injuries in children: risk factors and radiographic findings. World J Pediatr 9:169-174. https://doi.org/10.1007/s12519-0130416-2

Leonard H, Joffe A (2009) Children presenting to a Canadian hospital with trampoline-related cervical spine injuries. Paediatr Child Health 14:84-88. https://doi.org/10.1093/pch/14.2.84

Loder R, Schultz W, Sabatino M (2014) Fractures from trampolines: results from a national database, 2002 to 2011. J Pediatr Orthop 34:683-690. https://doi.org/10.1097/BPO.0000000000000189

McDermott C, Quinlan J, Kelly I (2006) Trampoline injuries in children. J Bone Joint Surg Br 88-B:796-798. https://doi.org/10.1302/0301620X.88B6.17647

Mulligan C, Adams S, Brown J (2017) Paediatric injury from indoor trampoline centres. Inj Prev 23:352-354. https://doi.org/10.1136/ injuryprev-2016-042071
Murphy C (2000) Trampoline injuries. Hazard 42:1-16

Paker N (2017) Trampoline injuries in the world and in Turkey. Turk J Phys Med Rehab 63:275-280. https://doi.org/10.5606/tftrd.2017. 1321

Paul S, Barnden J, Kane M (2016) Garden hazards: trampoline injuries. Br J Nurs 975 https://doi.org/10.1542/peds.2012-2082

Purcell L, Philpott J (2007) Trampolines at home and playgrounds: a joint statement with the Canadian Paediatric society. Clin J Sport Med 17: 389-392. https://doi.org/10.1097/JSM.0b013e318151401f

Rao D, McFaull S, Cheesman J, Do M, Purcell L, Thompson W (2019) The ups and downs of trampolines: injuries associated with backyard trampolines and trampoline parks. Paediatr Child Health 24: e19-e25. https://doi.org/10.1093/pch/pxy066

Rättyä J, Serlo W (2008) Using a safety net and following the safety instructions could prevent half the paediatric trampoline injuries. Eur J Pediatr Surg 18:261-265. https://doi.org/10.1055/s-20081038534

Royal Society for the Prevention of Accidents (2011) NHS Greater Glasgow and Clyde, trampoline safety. Available online at: http:// library.nhsggc.org.uk/mediaAssets/library/Trampoline_Safety_ Press_Quality.pdf. Accessed 28 Jul 2019

Royal Society for the Prevention of Accidents (2015) Garden trampolining. Available online at: https://www.rospa.com/rospaweb/docs/ advice-services/leisure-safety/garden-trampolining.pdf. Accessed 28 Jul 2019

Sharwood L, Adams S, Blaszkow T, Eager D (2018) Increasing injuries as trampoline parks expand within Australia: a call for mandatory standards. Aust NZ J Public Heal 42:153-156. https://doi.org/10. 1111/1753-6405.12783

The Guardian (2017) Jump! Why you visit a trampoline park at your peril. Available online at: https://www.theguardian.com/ lifeandstyle/2017/mar/20/visit-trampoline-park-at-your-perilinjuries. Accessed 28 Jul 2019

Wechsler B, Kim H, Hunter J (2001) Trampolines, children, and strokes. Am J Phys Med Rehabil 80:608-613. https://doi.org/10.1097/ 00002060-200108000-00012

Wilson G, Sameoto C, Fitzpatrick E, Hurley K (2018) Impact of a Canadian Pediatric Society position statement on trampolinerelated injuries at IWK Health Centre, Halifax, Nova Scotia. Cureus 10:e2609. https://doi.org/10.7759/cureus.2609

Wootton M, Harris D (2009) Trampolining injuries presenting to a children's emergency department. Emerg Med J 26:728-731. https:// doi.org/10.1136/emj.2008.069344

Yule M, Krishna S, Rahiri J, Hill A (2016) Trampoline-associated injuries are more common in children in spring. NZMJ 129:38-43

Publisher's note Springer Nature remains neutral with regard to jurisdictional claims in published maps and institutional affiliations. 